\title{
Mini View on Current Trends in Computer Sciences \& Applications
}

\author{
Ajay Rana ${ }^{1 *}$ and Manjeet Singh ${ }^{2}$ \\ ${ }^{1}$ Director ATPC, Amity University, Uttar Pradesh, India \\ ${ }^{2}$ Research Scholar, Amity University Noida, Uttar Pradesh, India
}

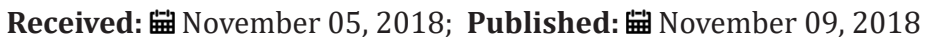

*Corresponding author: Ajay Rana, Director ATPC, AMITY University, Uttar Pradesh, India

\begin{abstract}
Computer science has contributed a lot for making the life of human being smooth. The recent developments in the field of computer science are proven to be more smarter and more applicable structures result from marrying the learning capability of the applications with the transparency and accuracy. Foundations of computer science applications highlights the advantages of integration making it a valuable resource for the students and researchers in engineering, computer science and applied mathematics. The authors' tried to lime light various applications that are an asset to industrial practitioners, corporates, academicians and professionals for control systems, data analysis and optimization tasks. With the continuous improvisation in the computer science applications the need of the young generation is fulfilled, and they can achieve their targets with the help of updated and enhanced support system. Authors are highlighting on current trends in computer sciences \& applications and further illustrate how these various technologies integrate with social and economic factors to provide a thorough solution to the real-world problems of the human being in every domain of life.
\end{abstract}

The authors demonstrated how a combination of both techniques and human interventions enhances control, decision-making and data analysis systems.

Keywords: Computer; Trends; VLSI Technology; Multiprocessor; Parallelism; Configurable Computing; DSP; Internet

\section{Introduction}

Although the very state forward answer for the latest trends in Computer science could be Machine learning, cloud computing and Artificial Intelligence. But basically, Industry build the software not only with what is new but by what customer problem can be solve easily and with good future scope and current market trends which covers customer requirements, this force towards innovation and create next generation products that can be quickly adopted for solving new use cases by Connecting to new data sources easily.

Top technologies which are in current trends in computer science \& Application are as below:
A. Deep learning or Machine learning (ML).
B. Digital currencies: Example Bitcoin
C. Blockchain.
D. IoT
E. Robotics
F. Big Data Analytics.
G. Cloud Computing
H. Cyber Security
I. Virtual Reality
J. Predictive Analytics

The emerging areas that are seeking attention of many researchers in the field of computer science are designed and developed according to the latest market trends. Now a day trends in information technologies are directly or indirectly associated with the customer centric approach. One of the latest technology like computational biology where in the gathering and processing of biological data with the use of computer programs. This technology covers under Bio Informatics, which works with the combination of computers and living beings. It converts the biological data into readable format. This is helping the medical science a lot. Another most promising technology of today is Data Science or Big Data. 
This field has a very large and promising scope of research and development considering the huge volume of data being produced by organizations and individually in different sectors worldwide. It deals with the storage processing and analysing the massive data stored across the world in various organization and data centres.

The existence of newest trend of Virtual Reality cannot be ignored. The biggest stakeholders of VR applications are medical science, physical sciences, environment, businesses, space industry and entertainment industry. VR produces the set of the data which is used to develop new models training methods, communications and interaction. The major disadvantages in the use of VR application are time, cost and technological limitations. But because of its support system it is expected to become more affordable in future, today's generation is grown up having technology at their disposal. They are familiar with smart phones, tablets therefore VR Developments will also increase in number of professionals more acquainted with the technology. Cloud Computing has already become the area of attention by most of the researcher and scientists. Cloud provider is basically data or internet provider. This plays an important role in various fields of business, computing security etc. This application works on the shared pools of configurable computer system recourses and higher-level services that ease the managerial effort with leads to economics of scale and development. It helps in running business more efficiently.

Cloud computing eliminates the capital expenses of buying hardware and software along with other related expenses. Business has become very flexible as cloud computing services are available on demand that leads to delivering right amount of IT resources resulting in scale elasticity. Lots of 'Racking and Stacking' task is being eliminated as cloud computing removes the needs for many of these tasks resulting in more time devotion towards more important business goals. Cloud computing services run on a worldwide network regularly upgraded data centres. This reduces network latency for application and improvises efficient computing hardware. It also helps in providing security to the data, apps from potential threats. However, several types of cloud computing is operational to help offer right solution for your needs like public, private and hybrid.

Deep Learning or Machine Learning is sub set of artificial intelligence and in today's trends it's one of most widely used computer science application, the ability of ML is to self-trend from data or able to learn from its own experiences, which can improve from application behaviour or experience without being explicitly programmed. Machine learning focuses on the development of computer programs that can access data and use it learn for themselves.

\section{Example:}

A good example can be a Navigation system or MAP application which initially developed with limited data but later on when this application gets used its design in a way so it trained itself to predict the best possible path.

Google search, uber, Pay Pal, Facebook are the good example of ML and these actually improving the usability of their services by applying deep learning algorithms. Below is the comparative example where one sector is using Machin learning and takin its benefits and other one is moving very slowly in digital and it's far behind (Figure 1). Machine learning can help banks, insurers, and investors make smarter decisions in a number of different areas:

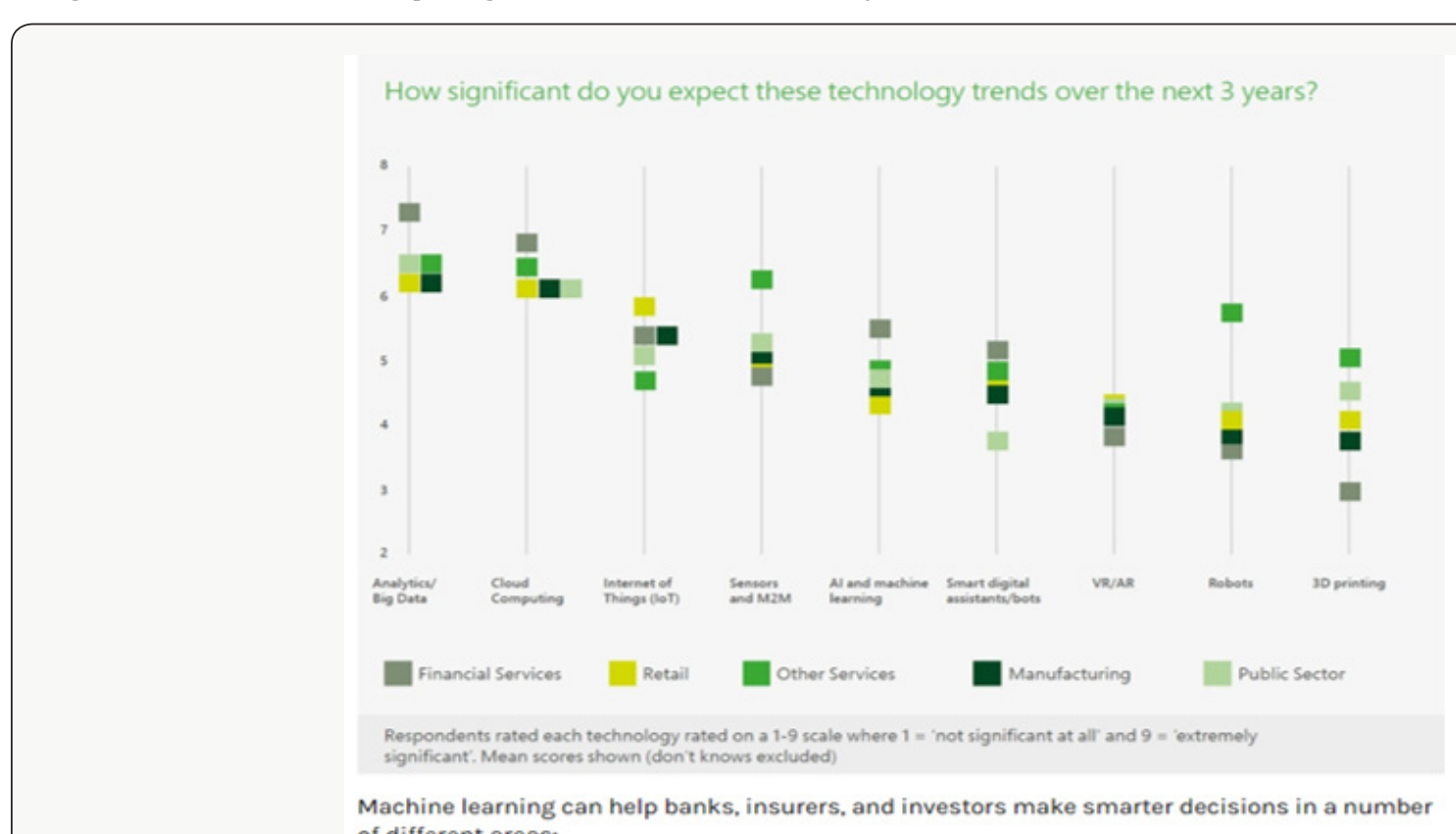

Figure 1 
a) Customer and Client Satisfaction: Machine learning helps financial services on below key points.

i. By analysing user activity.

ii. Smart machines can spot a potential account closure before it occurs.

b) Reacting to Market Trends: Another aspect can be cover by using a good ML algorithm which is generating the alerts or by preserving the trained to track trading volatility or manage wealth and assets on behalf of an investor.

c) Calculating Risk: Good ML algorithms can analyse datasets and based on the dataset (credit scores, spending patterns, financial data etc.) to accurately assess risk in both insurance underwriting and loan assessments, tailoring them to a specific customer profile.

\section{Conclusion}

Trends in Computer Sciences \& Applications changed drastically the life of one and all. Be it a student learning or business corporate or any other professional, computer science and its applications are extending their updated support system to give more effective performance infrastructure in every sphere. Recent developments gives acceleration to the development of a Digital currency or digital money introduction in the form of digital, Blockchain a digital ledger in which transactions made in cryptocurrency. The contribution is endless and so the developments in this field are boundless.

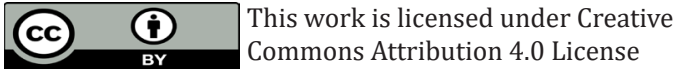

To Submit Your Article Click Here: Submit Article

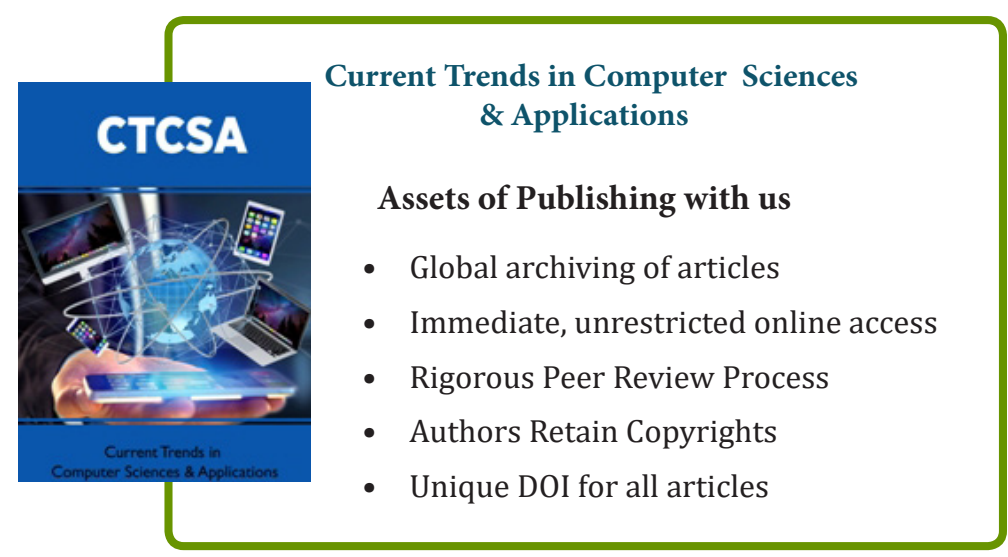

